\title{
Chave pictórica para os gêneros de Tabanidae (Insecta: Diptera) do bioma Campos Sulinos, Rio Grande do Sul, Brasil
}

\author{
Tiago Kütter Krolow ${ }^{1,4}$, Rodrigo Ferreira Krïger ${ }^{2}$ \& Paulo Bretanha Ribeiro ${ }^{3}$
}

Biota Neotropica $v 7(n 2)$

http://www.biotaneotropica.org.br/v7n2/pt/abstract?identification-key+bn03307022007

\author{
Recebido em 12/09/06 \\ Versão Reformulada recebida em 10/05/07 \\ Publicado em 18/06/07
}

\begin{abstract}
${ }^{1}$ Instituto Nacional de Pesquisas da Amazônia, Divisão do Curso de Entomologia, Av. André Araújo, 2936, Bairro Aleixo, CP 478, CEP 69083-000, Manaus, AM, Brasil

${ }^{2}$ Universidade Federal de Viçosa - UFV, Departamento de Biologia Animal,

Av. P. H. Rolfs, s/n, Campus Universitário, CEP 36571-000, Viçosa, MG, Brasil, http://www.insecta.ufv.br

${ }^{3}$ Universidade Federal de Pelotas, Instituto de Biologia, Departamento de Microbiologia e Parasitologia,

Campus Universitário, s/n, CP 354, CEP 96010-900, Pelotas, RS, Brasil, http://www.ufpel.tche.br

${ }^{4}$ Autor para correspondência: Tiago Kütter Krolow, e-mail: krolow@inpa.gov.br, http://pg.inpa.gov.br
\end{abstract}

\section{Abstract}

Krolow, T.K.; Krüger, R.F. and Ribeiro, P.B. Illustrated key for Tabanidae (Insecta: Diptera) genera of Campos Sulinos biome, Rio Grande do Sul, Brazil. Biota Neotrop. May/Aug 2007 vol. 7, no. 2. http://www.biotaneotropica.org.br/v7n2/pt/abstract?identification-key+bn03307022007. ISSN 1676-0603.

Tabanids were collected and preserved along four years (2002-2006) in southern Rio Grande do Sul, Brazil. A list of 30 species is presented along with an illustrated key and diagnoses for identification of the 15 genera found in the area. Nine species are registered for the first time in the state of Rio Grande do Sul.

Keywords: horse flies, species, diversity, pampa, public health.

\section{Resumo}

Krolow, T.K.; Krüger, R.F. and Ribeiro, P.B. Chave pictórica para os gêneros de Tabanidae (Insecta: Diptera) do bioma Campos Sulinos, Rio Grande do Sul, Brasil. Biota Neotrop. May/Aug 2007 vol. 7, no. 2. http://www.biotaneotropica.org.br/v7n2/pt/abstract?identification-key+bn03307022007. ISSN 1676-0603.

Foram realizadas coletas de tabanídeos ao longo de quatro anos (2002-2006) no extremo sul do Rio Grande do Sul, Brasil. Apresenta-se uma lista com 30 espécies, além de chave pictórica e diagnoses para identificação dos 15 gêneros encontrados na região. Nove espécies são registradas pela primeira vez no estado do Rio Grande do Sul.

Palavras-chave: mutucas, espécies, diversidade, pampa, saúde pública. 


\section{Introdução}

Na região sul do Brasil, os tabanídeos são conhecidos popularmente como "mutucas" ou "moscas dos cavalos". São dípteros robustos e os adultos variam de 5 a $25 \mathrm{~mm}$ de comprimento, apresentando cabeça hemisférica mais larga do que o tórax. Os machos são holópticos e fitófagos (florículas), enquanto que as fêmeas são dicópticas, geralmente de hábito hematófago, necessário para a maturação dos ovócitos. As mutucas representam um grande incômodo ao homem e aos animais domésticos e selvagens, por causa da picada dolorosa e o elevado grau de hematofagia que as fêmeas apresentam. São capazes de ingerir até 0,5 $\mathrm{mL}$ de sangue por indivíduo e mais sangue pode ser perdido por causa do escoamento pós picada, o que gera reações como nódulos dérmicos que podem servir como alimentação secundária ou para oviposição de outras moscas, como as causadoras de miíases (Foil \& Hogsette 1994). Segundo Krinsky (1976), as mutucas são capazes de transmitir cerca de 35 agentes patogênicos, entretanto, na região Neotropical, pouco se conhece sobre a capacidade de transmissão e veiculação, principalmente pela falta de levantamentos taxonômicos e reconhecimento das espécies associadas às regiões de pecuária.

Os tabanídeos compreendem 4290 espécies distribuídas em 137 gêneros. Na região Neotropical já foram registradas cerca de 1172 espécies em 65 gêneros (Fairchild \& Burger 1994). Conforme Morrone (2005), o extremo sul do Rio Grande do Sul situa-se nos pampas, biogeograficamente pertencendo à mesma formação do Uruguai e de boa parte da Argentina, o que aumenta a similaridade da fauna e flora destas regiões. Esta similaridade com a fauna argentina foi observada em trabalhos realizados no sul do Brasil por Lutz et al. (1918) e Leclercq (1965), que coletaram no Rio Grande do Sul e na região de Pelotas, respectivamente.

Este trabalho foi realizado por causa da falta de dados e das dificuldades para identificação de tabanídeos na região sul, em parte porque a maioria das espécies está depositada na Argentina e porque existe uma grande dificuldade por parte dos profissionais das áreas de sanidade animal e ecologia de comunidades em identificar os principais grupos de Tabanidae. A fim de facilitar o estudo desse grupo temos o objetivo de fornecer uma lista de espécies coletadas no extremo sul do Rio Grande do Sul e uma chave pictórica com diagnoses para identificação de gêneros, permitindo um acesso fácil a diversos profissionais e estudantes relacionados às áreas de saúde pública e conservação.

\section{Material e Métodos}

Os espécimes de Tabanidae foram obtidos de coletas realizadas em quatro pontos do bioma Campos Sulinos, extremo sul do Rio Grande do Sul. Foram utilizadas armadilhas do tipo Malaise (Townes, 1972). As armadilhas foram instaladas nos municípios de Arroio Grande ( $32^{\circ} 13$ ' 22" S e 53 $11^{\prime}$ '57" W), Capão do Leão ( $31^{\circ} 48^{\prime} 16^{\prime \prime} \mathrm{S}$ e $\left.52^{\circ} 24^{\prime} 13^{\prime \prime} \mathrm{W}\right)$, Morro Redondo ( $31^{\circ} 40^{\prime} 22^{\prime \prime} \mathrm{S}$ e $52^{\circ} 35^{\prime} 30^{\prime \prime} \mathrm{W}$ ) e Pelotas ( $31^{\circ} 44^{\prime} 39^{\prime}$ ' S e $52^{\circ} 13^{\prime} 22^{\prime}$ 'W). O material amostrado foi agrupado e analisado semanalmente conforme a data de retirada e local. As coletas foram realizadas entre julho de 2002 e junho de 2004, totalizando 104 amostras para cada localidade. Adicionalmente houve coletas mensais no município de Morro Redondo ( $31^{\circ} 33$ ' 17,13' S e 52 36'24,07' W), no período de outubro de 2005 a abril de 2006 , as quais foram realizadas com redes entomológicas utilizando um eqüino como atrativo.

Os espécimes foram identificados de acordo com a Coleção de Tabanidae do Museo de La Plata. Os desenhos e fotos foram realizados com a utilização dos espécimes obtidos nas coletas. A confecção da chave foi baseada em Fairchild (1969) e Coscarón \& Papavero (1993). As diagnoses seguiram Coscarón (1968, 1974b, 1975a, 1976a, 1976c, 1978, 1979, 1979b \& 2001), Coscarón \& Philip
(1967), Coscarón \& Fairchild (1976) e Wilkerson \& Coscarón (1984). O material foi depositado na Coleção de Entomologia "Pe. Jesus Santiago Moure", Departamento de Zoologia (DZUP), Universidade Federal do Paraná.

\section{Resultados}

Foram identificadas 30 espécies (Tabela 1), distribuídas em três subfamílias (Pangoniinae, Chrysopsinae e Tabaninae), quatro tribos e 15 gêneros. Nove espécies tem seu primeiro registro para o extremo sul do Rio Grande do Sul.

\section{Scaptia Lutz, 1918}

Diagnose: Espécies de tamanho médio a grande. Olhos e frontoclípeo pilosos. Antena apresenta oito anuli. Normalmente a probóscide é esbelta com uma pequena labela, o tamanho da probóscide é pelo menos três vezes maior que o segundo segmento do palpo. Células R5 e CuA1 geralmente abertas (Wilkerson \& Coscarón 1984).

Tabela 1. Lista das tribos e espécies de Tabanidae do extremo sul do Rio Grande do Sul. * Primeira ocorrência para o Rio Grande do Sul.

\begin{tabular}{|c|c|}
\hline Tribos & Espécies \\
\hline Scionini & * Scaptia longipennis (Ricardo), 1902 \\
\hline Scionini & Fidena longipalpis Enderlein, 1925 \\
\hline Chrysopsini & * Chrysops brevifascius Lutz, 1909 \\
\hline Chrysopsini & Chrysops crucians Wiedemann, 1828 \\
\hline Chrysopsini & * Chrysops flavoscutellatus Kröber, 1926 \\
\hline Chrysopsini & Chrysops laetus Fabricius, 1805 \\
\hline Chrysopsini & Chrysops leucospillus Wiedemann, 1828 \\
\hline Chrysopsini & Chrysops nigricorpus Lutz, 1911 \\
\hline Chrysopsini & Chrysops varians Wiedemann, 1828 \\
\hline Diachlorini & $\begin{array}{l}\text { * Acanthocera aureoscutellata } \\
\text { Henriques \& Rafael, } 1992\end{array}$ \\
\hline Diachlorini & Acanthocera exstincta (Wiedemann), 1828 \\
\hline Diachlorini & Catachlorops plagiatus (Brèthes), 1910 \\
\hline Diachlorini & * Chlorotabanus parviceps (Kröber) 1934 \\
\hline Diachlorini & Dasybasis missionum (Macquart), 1838 \\
\hline Diachlorini & Dichelacera alcicornis (Wiedemann), 1828 \\
\hline Diachlorini & * Dichelacera fuscipes Lutz, 1915 \\
\hline Diachlorini & Dichelacera unifasciata Macquart, 1838 \\
\hline Diachlorini & Lepiselaga albitarsis Macquart, 1850 \\
\hline Diachlorini & * Leucotabanus albibasis (Brèthes), 1910 \\
\hline Diachlorini & $\begin{array}{l}\text { * Phaeotabanus limpidapex } \\
\text { (Wiedemann), } 1828\end{array}$ \\
\hline Diachlorini & * Stenotabanus obscurus Kröber 1929 \\
\hline Diachlorini & Stypommisa rubrithorax (Macquart) 1838 \\
\hline Tabanini & $\begin{array}{l}\text { Poeciloderas quadripunctatus } \\
\text { (Fabricius), } 1805\end{array}$ \\
\hline Tabanini & Tabanus acer Brèthes, 1910 \\
\hline Tabanini & Tabanus claripennis (Bigot), 1892 \\
\hline Tabanini & Tabanus fuscofasciatus Macquart, 1838 \\
\hline Tabanini & Tabanus fuscus Wiedemann, 1819 \\
\hline Tabanini & Tabanus pungens Wiedemann, 1828 \\
\hline Tabanini & Tabanus sorbillans Wiedemann, 1828 \\
\hline Tabanini & Tabanus triangulum Wiedemann, 1828 \\
\hline
\end{tabular}




\section{Fidena Walker, 1850}

Diagnose: Espécies Grandes, de 11-18 mm, apresenta coloração variável desde castanho amarelado até enegrecidas. Seus olhos não possuem ornamentações, geralmente com pêlos compridos e abundantes. Fronte estreitada, sem calo frontal, porem pode apresentar uma área brilhante simulando um calo. Tubérculo ocelar proeminente com três ocelos bem desenvolvidos. Subcalo geralmente polinoso, probóscide comprida e esclerotinizada. Antena com flagelo comprido. Palpo lateralmente achatado. Asa subhialina, freqüentemente com tons castanhos, sem ornamentações, geralmente apresentando as células posteriores R5 e m3 fechadas. Presença de esporões apicais na tíbia posterior (Coscarón 2001).

\section{Chrysops Meigen, 1800}

Diagnose: Olhos nus, com bandas ou manchas não paralelas. Fronte mais larga que alta, calo frontal elevado. Tubérculo ocelar presente e elevado, com três ocelos bem desenvolvidos. Subcalo reduzido. Face com áreas brilhantes. Antenas relativamente compridas, com escapo e pedicelo mais compridos que largos, placa basal sem ângulo dorsal. Palpo com escassa polinosidade. Basicosta nua, asas geralmente com manchas na margem anterior e com uma grossa banda transversal, veia R4 sem apêndice. Coxas anteriores largas, presença de espinhos nas tíbias posteriores (Coscarón 1979).

\section{Acanthocera Macquart, 1834}

Diagnose: Espécies de tamanho mediano, com olhos violáceos apresentando duas bandas esverdeadas que se fusionam. Antenas compridas, apresentando escapo e pedicelo finos. Fronte larga e divergente, com calo frontal largo. Frontoclípeo inflado e brilhante, e face brilhante. Basicosta nua, asas com áreas sombreadas principalmente na região anterior. Tórax com um pequeno par de bandas finas anteriores, de coloração amarelada. Abdome geralmente com uma constrição na parte anterior, dando um aspecto vespiforme, apresenta ainda bandas finas na porção posterior dos tergitos I e II (Coscarón 1978).

\section{Catachlorops Lutz, 1913}

Diagnose: Espécies de tamanho mediano, com coloração variando de castanho claro amarelado a escuro, olhos sem bandas, fronte relativamente estreita, com calo prolongado em uma longa lista que ultrapassa a metade da altura da fronte. Tubérculo ocelar reduzido e ocelos pouco visíveis, subcalo polinoso. Antena com forte apêndice dorsal que frequentemente alcança o primeiro anulus. Palpos largos, chatos e com polinosidade curta e abundante. Basicosta com cerdas. Abdome com ou sem triângulos medianos posteriores (Coscarón 1975).

\section{Chlorotabanus Lutz, 1913}

Diagnose: Espécies de tamanho mediano, com coloração esverdeada, e pilosidade amarelada, olhos sem bandas e sem pêlos. Antena com placa basal mais larga que o estilo e sem apêndice, com ângulo dorsal não muito elevado, palpos com segundo segmento inflado na base, fronte ligeiramente convergente, sem calo frontal e sem ocelos. Basicosta nua, asas hialinas, em algumas espécies com pequenas manchas negras. Tórax, abdome e apêndices com a mesma coloração (Coscarón 1976c).

\section{Dasybasis Macquart, 1847}

Diagnose: Espécies de tamanho mediano. Fronte variável, mas geralmente do tamanho da base do calo frontal, ou se reduzida, não forma projeção apical em forma de quilha. Coloração abdominal variável (Coscarón \& Philip 1967).

\section{Dichelacera Macquart, 1838}

Diagnose: Espécies de tamanho mediano, coloração castanho. Olhos verdes azulados, com banda transversa geralmente sem pêlos, fronte relativamente estreita, calo geralmente tocando os olhos, tubérculo ocelar reduzido, ocelos ausentes ou pouco nítidos. Subcalo polinoso, com antenas apresentando placa basal prolongada, com ou sem apêndice, palpos compridos. Basicosta nua, asas com manchas em formas variáveis, geralmente sem apêndice na veia R4. Abdome sem muitas ornamentações (Coscarón 1974).

\section{Lepiselaga Macquart, 1838}

Diagnose: Espécies pequenas, menores de $10 \mathrm{~mm}$, apresenta olhos negros com bandas, sem ocelos. Subcalo, frontoclípeo e palpos brilhantes. Antenas com a placa basal mais longa que o estilo. Palpos inflados. Tíbias infladas com tarsos esbranquiçados. Basicosta nua, asas com manchas, célula discal com estreitamento central. Abdome afinado bruscamente a partir do VI tergito (Coscarón 1968).

\section{Leucotabanus Lutz, 1913}

Diagnose: Espécies de tamanho médio, com tonalidade de castanho a enegrecido. Olhos grandes sem pêlos e sem bandas, fronte estreita com calo alargado que não toca os olhos, tubérculo ocelar relativamente elevado. Antenas com placa basal sem angulação saliente. Asas hialinas, basicosta com abundantes cerdas e sem apêndice na veia r4. Abdome relativamente largo (Coscarón 1976).

\section{Phaeotabanus Lutz, 1913}

Diagnose: Espécies de tamanho médio a grande, de cor castanha, olhos negros com tons esverdeados, sem bandas, fronte estreita, calo não toca a margem interna dos olhos e segue em prolongada crista dorsal. Tubérculo ocelar e ocelos ausentes, subcalo e face polinosos, antenas apresentam a placa basal com um ângulo amplo e com ápice alongado. Basicosta nua, asa frequentemente com manchas e geralmente com apêndice na veia R4 presente (Coscarón 1978).

\section{Stenotabanus Lutz, 1913}

Diagnose: Espécies de tamanho pequeno, olhos com duas ou três bandas claras sobre o fundo escuro, quase sem pêlos, quando aparecem muito curtos e escassos. Fronte ligeiramente estreitada, de lados paralelos ou ligeiramente convergentes, calo brilhante prolongado em uma linha média, tubérculo ocelar reduzido ou ausente. Subcalo polinoso e sem pêlos, antena com placa basal sem espinho, mais comprida que larga e tão comprida quanto o estilo. Palpos alargados. Tórax com coloração castanho a castanho acinzentado. Asas geralmente hialinas, com basicosta nua, podendo apresentar ou não apêndice na veia R4. Abdome alargado, frequentemente com uma banda mediana longitudinal (Coscarón 1975).

\section{Stypommisa Enderlein, 1923}

Diagnose: Espécies relativamente pequenas (8-12 mm), coloração castanho escuro, olhos negros com tonalidade esverdeada ou violácea, sem bandas e geralmente sem pêlos. Fronte estreita mais alta que larga, calo não toca os olhos. Geralmente com tubérculo ocelar. Antenas sem angulação dorsal. Asas geralmente escurecidas nos cruzamentos das veias. Abdome com triângulos no dorso, basicosta sem cerdas (Coscarón 1976c).

\section{Poeciloderas Lutz, 1921}

Diagnose: Espécies de tamanho mediano, coloração castanho. Abdome com uma fileira central de triângulos, e bandas oblíquas laterais em cada tergito. Apresenta o escapo globoso e prolongado dorsalmente, frequentemente mais largo que placa basal. Olhos 
longado em uma lista. Basicosta com cerdas, asas com manchas nos intercruzamentos das veias (Coscarón \& Fairchild 1976).

\section{Tabanus Linnaeus, 1758}

Diagnose: Espécies de tamanho mediano a grande, possuem olhos sem pêlos, com ou sem bandas, triangulo ocelar chato e sem ocelos. Fronte mais alta que larga, com calo frontal bem desenvolvido, antenas com placa basal geralmente com ângulo agudo elevado, mas sem espinho dorsal, palpo com segundo segmento longo e coberto de pêlos. Tórax geralmente de uma cor. Basicosta com cerdas, asas geralmente hialinas e sem bandas, se escurecidas, ocorre de forma homogênea ou ao longo das veias longitudinais. Com ou sem apêndice na veia R4.
Abdome geralmente ornamentado com triângulos medianos no dorso, e nas margens bandas oblíquas em cada tergito (Coscarón 1979).

\section{Agradecimentos}

Ao Dr. Sixto Coscarón (Museo de La Plata) pelo auxílio na identificação das espécies. Ao Dr. Claudio Jose Barros de Carvalho, pelo depósito do material na coleção de Entomologia do Departamento de Zoologia da UFPR. E ao Dr. Augusto Loureiro Henriques (Instituto Nacional de Pesquisas da Amazônia) pela leitura e sugestões do texto.

\section{Chave pictórica para os gêneros de Tabanidae (Insecta: Diptera) do bioma Campos Sulinos, Rio Grande do Sul, Brasil}

1 -Flagelo geralmente com oito (ou sete) anuli distintos (Figura 1). Ocelos (Figura 2) e espinhos apicais (Figura 3) da tíbia posterior pre-

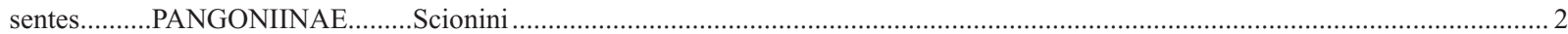
-Flagelo apresentando uma placa basal e quatro ou menos anuli (Figura 4). Ocelos e espinhos apicais da tíbia posterior presentes, reduzidos ou ausentes

2 -Comprimento da probóscide raramente superior a duas vezes a altura de cabeça (Figura 5). Palpo achatado, geralmente curto e largo ..

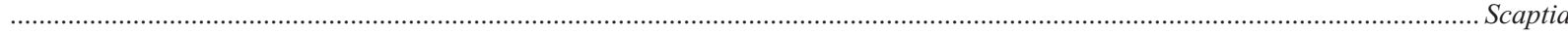
-Comprimento da probóscide geralmente superior a duas vezes a altura da cabeça (Figura 6). Palpo plano na região superior. Célula m3 aberta, célula r5 normalmente fechada, sempre comprimida (estreitada) (Figura 7). Fronte plana, sem protuberância....................Fidena

3 -Ocelos presentes (Figura 8). Espinhos apicais da tíbia posterior (vista ventral) presentes, pouco diferenciados do restante das cerdas

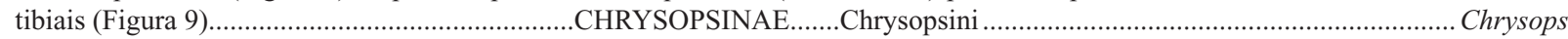
-Ocelos funcionais ausentes, no máximo com ocelos vestigiais. Espinhos apicais da tíbia posterior ausentes (Figura 10).. TABANINAE

4 -Basicosta sem cerdas (Figura 11) ou basicosta coberta com cerdas, mas estas em menor densidade que nas adjacências da veia costa (Figura 12). Freqüentemente com um ou mais dos seguintes caracteres: ocelos vestigiais ou apenas tubérculo ocelar presente; longo espinho dorsal

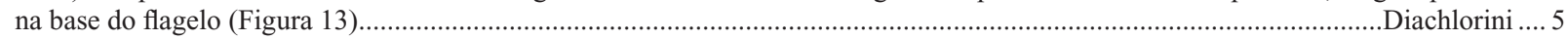
-Basicosta densamente coberta de cerdas, tão densamente como nas adjacências da veia costa (Figura 14). Labela membranosa. Ocelos ausentes, tubérculo ocelar geralmente presente. Raramente com algumas das especializações acima................ Tabanini.................... 14

5 -Com um ou ambos dos seguintes caracteres: base do flagelo com espinho agudo ou prolongamento dorsal (Figura 13); labela compacta

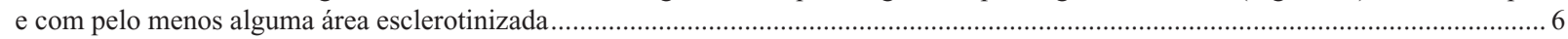
-Sem os caracteres acima. Base do flagelo no máximo com angulação obtusa dorsalmente (Figura 15) e a labela é completamente membranosa.

7 -Espécies de tamanho médio a grande porte, com 9,6 - $14 \mathrm{~mm}$ de comprimento de asa, tórax sem faixas, não mimética (sem aspecto vespiforme). Calo frontal pequeno e estreito na base, geralmente com o ápice em crista (Figura 18). Asa geralmente com padrão escuro, algumas vezes hialina Phaeotabanus

-Outra combinação de caracteres

.8

8 -Calo frontal mais estreito que a fronte (Figura 19), se não, triangular com extensão superior em crista e os ângulos inferiores apenas tocam os olhos. Em vida, olhos unicoloridos ou bicoloridos, muito raramente com listras .............................................Catachlorops -Calo frontal tão largo quanto à fronte (Figura 20), caso contrário fronte mais larga na base, calo arredondado e protuberante, com clípeo e parafaciália apresentando áreas lisas. Em vida, olhos com pelo menos uma listra mediana transversal escura, raramente unicolorido. Espécies com tíbias delgadas.

9 -Antena longa (Figura 21). Corpo freqüentemente com distinta constrição na base do abdômen (Figura 22). Aspecto vespiforme. Espinho dorsal da base do flagelo pode estar ausente, ser curto ou alcançar o primeiro anulus. Asa com pelo menos a borda anterior enfuscada .. Acanthocera -Antena mais curta. Corpo sem constrição na base do abdômen (Figura 23). Espinho dorsal da base do flagelo sempre presente, curto ou longo. Asa com manchas variáveis, geralmente com faixa diagonal irregular.

Dichelacera 
10 -Célula discal da asa estreitada no meio (Figura 24). Asa preta na maior parte, com pequenas áreas hialinas, ápice hialino. Palpo inflado (Figura 25) e brilhante. Tíbias infladas (Figura 26). Escapo antenal longo (Figura 27) ..........episelaga -Célula discal da asa normal, sem estreitamento no meio (Figura 28). Tíbias geralmente delgadas (Figura 29) ................................. 11

11 -Geralmente moscas pequenas, com olhos nus, com duas bandas transversais em vida, claras e escuras. A clara geralmente esverdeada e a escura em tom púrpura ou enegrecido. Fronte moderadamente larga, freqüentemente com um remendo escuro de pêlos na região mediana (Figura 30). Calo geralmente quadrado ou arredondado tão largo como a fronte (Figura 30) (se a fronte é muito estreita, como o ápice do calo, e possui olhos sem bandas ver (Stypommisa).

Stenotabanus

-Outra combinação de caracteres. 12

12 -Calo com a base larga, tocando a margem interna dos olhos e a base da fronte em toda sua extensão (Figura 31), ou calo subtriangular que não chega à margem interna, nem ocupa toda a base da fronte...... Dasybasis -Calo frontal claviforme (Figura 18) ou espiniforme (Figura 19)

13 -Asa hialina ou tingida por igual, célula costal geralmente escurecida, nunca com manchas nas veias transversais, ou apenas escurecida no ápice. Calo frontal claviforme ou espiniforme. Abdômen preto a marrom, quase sempre com faixas pilosas, geralmente no quarto tergito. Escutelo e geralmente escuto com pruinosidade clara e pêlos claros. Apêndice na forquilha da veia r4 ausente (Figura 32). Olhos escuros, sem faixas. Basicosta esparsamente a densamente pilosa ...

Leucotabanus -Asa com manchas pelo menos nas veias transversais da célula discal, geralmente com enfuscação apical. Apêndice na forquilha da veia r4 geralmente presente (Figura 33). Olhos sem faixas, verdes ou bronze. Calo frontal claviforme ou espiniforme. Basicosta raramente nua Stypommisa

14 -Vértice da cabeça com tubérculo ocelar pequeno e arredondado (Figura 34). Escapo antenal relativamente expandido, mais largo que o flagelo (vista frontal). Asa com todas as veias transversais proeminentemente com manchas (Figura 35). Célula r5 fechada ou estreitada (Figura 36) Poeciloderas

-Vértice com no máximo uma pequena mancha. Nunca com labela esclerotinizada ou basicosta glabra. ...Tabanus

Terminologia e morfologia de Tabanidae:

1. Cabeça (Dichelacera)

2. Antena (Poeciloderas)

3. Perna (Tabanus)

4. Asa (Tabanus)

Cabeça: ant - antena; $\mathbf{c f}$ - calo frontal; fc - face; fr - fronte; gn - gena; ocl - olho composto; pmx - palpo maxilar; prb - probóscide; sc - subcalo; vtc - vértice.

Antena: anl - anulu; esc - escapo; est - estilo; flg - flagelo; ped - pedicelo; p.bsl. - placa basal.

Perna: cx - coxa; fr - fêmur; tb - tíbia; tr - trocânter; ts - tarso.

Asa (Células): bm - basilar-média; br - basilar-radial; c - costal; cuA1 - cúbito-anal; cup - cubital-posterior; d - discal; la - lobo anal; $\mathbf{m 1}$ - medial1; m2 - medial2; m3 - medial3; r1 - radial1; r2 +3 - radial2 + 3; r4 - radial4; r5 - radial5; sc- subcostal.

Asa (veias): A1 + CuA2 - Anal1 + cúbito-ana12; Bc - basicosta; C - costa; CuA1 - cúbito-anal1; M1 - média1; M2 - média2; M3 média3; $\mathbf{R} 1$ - rádio1; $\mathbf{R 2}+\mathbf{3}$ - rádio $2+3 ; \mathbf{R} 4$ - rádio4; $\mathbf{R} 4+\mathbf{5}$ - rádio4 + 5; $\mathbf{R 5}$ - rádio5; $\mathbf{S c}$ - subcosta.
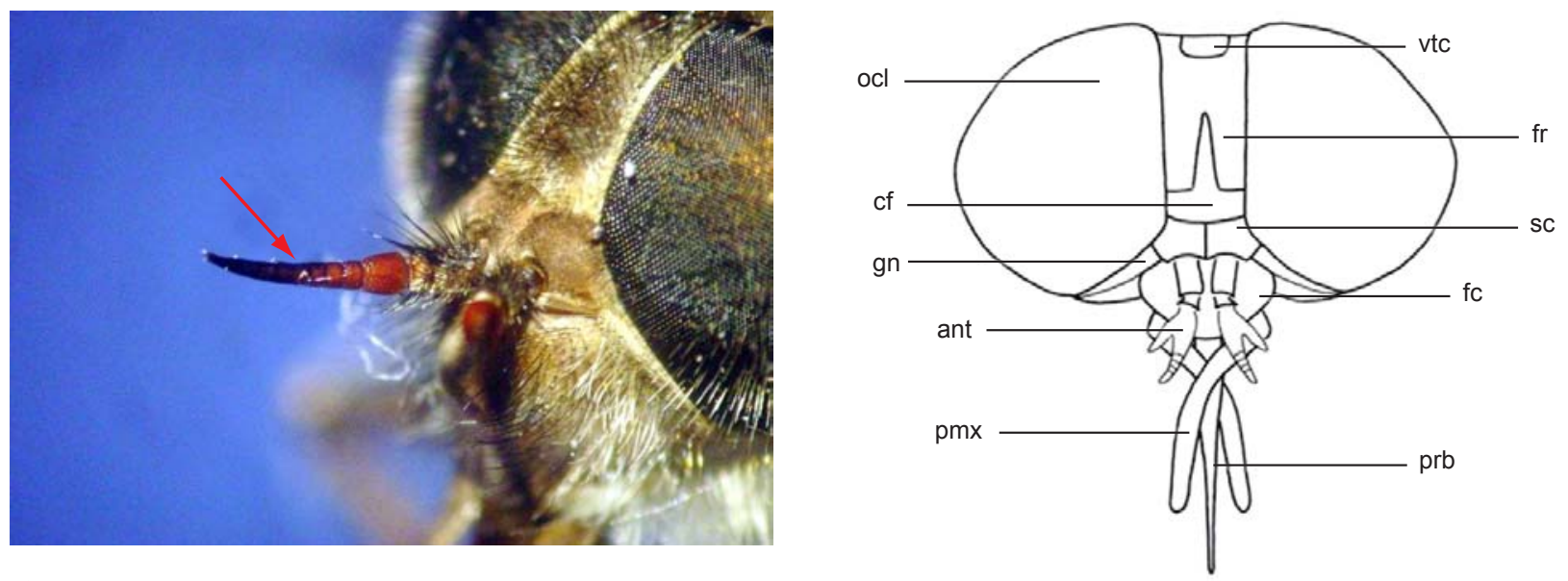

Figura 1. Flagelo com oito (ou sete) anuli distintos (Scaptia).

Figure 1. Flagellum with eight (or seven) distinct anuli (Scaptia). 

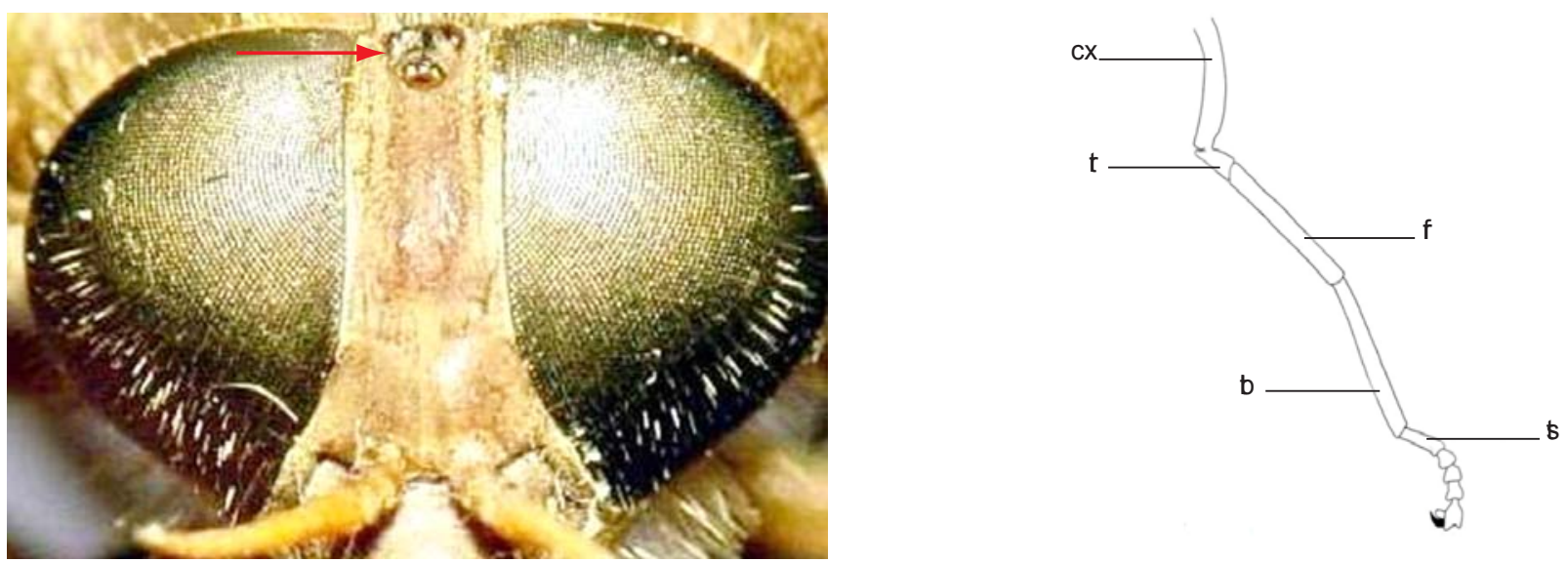

Figura 2. Ocelos presentes (Fidena).

Figure 2. Oceli present (Fidena).
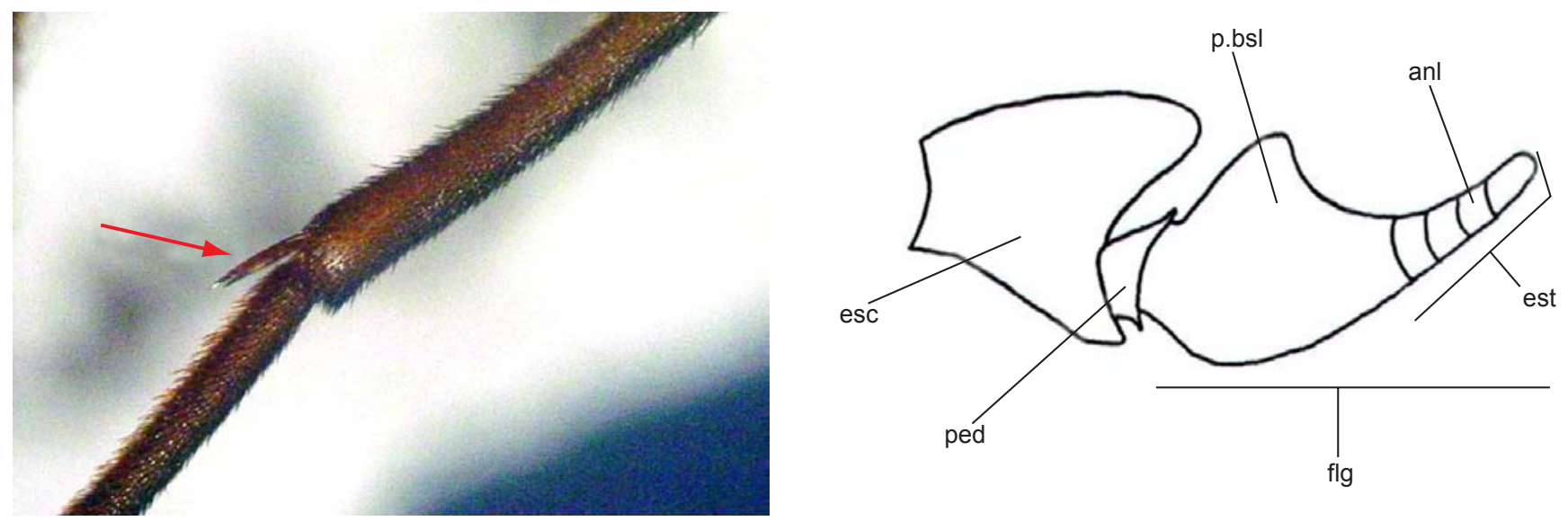

Figura 3. Espinhos apicais da tíbia posterior presentes (Fidena)

Figure 3. Apical spines on the posterior tibia present (Fidena).
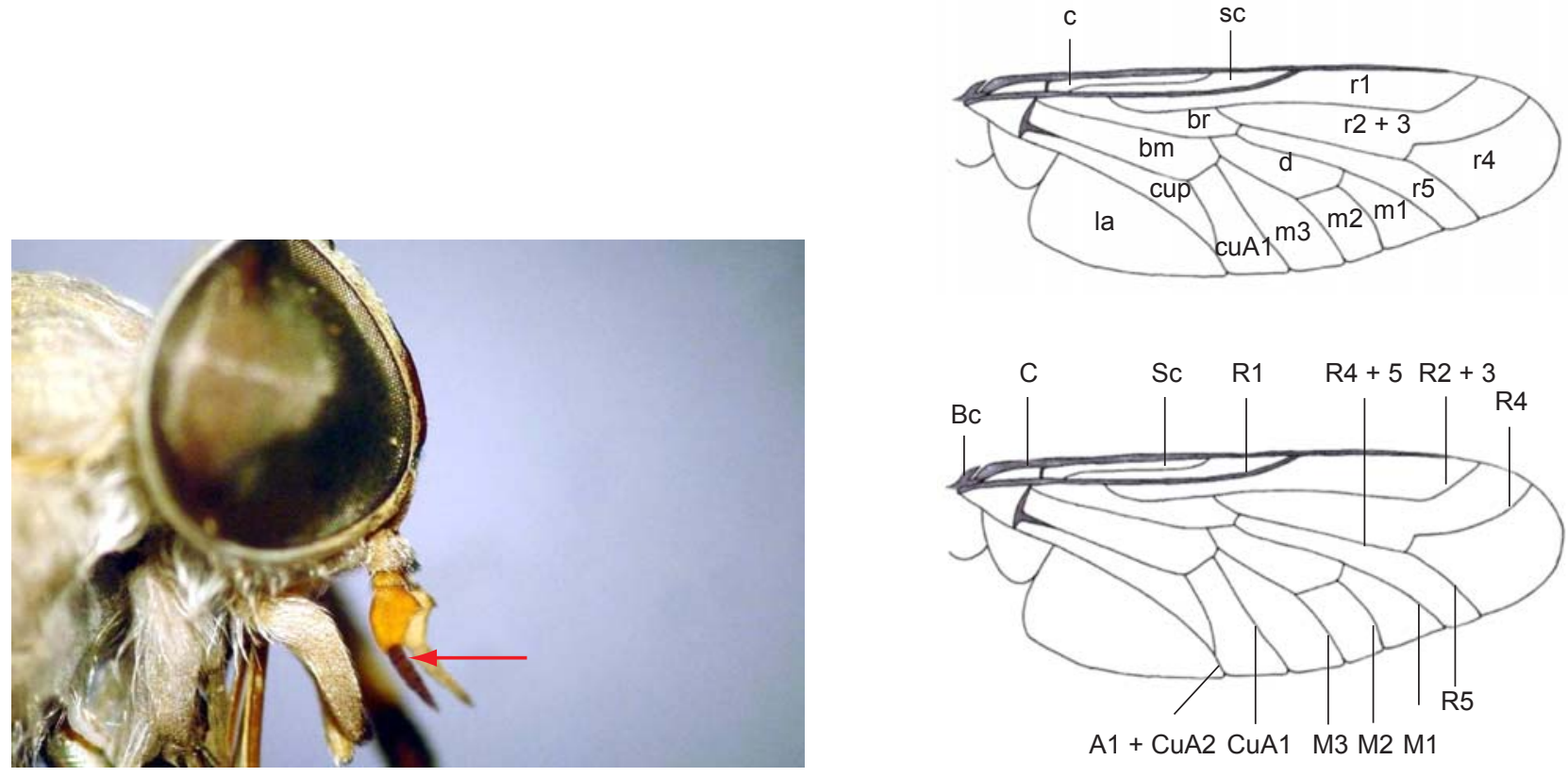

Figura 4. Flagelo apresentando uma placa basal e quatro ou menos anuli (Leucotabanus).

Figure 4. Flagellum with a basal plate and four or fewer anuli (Leucotabanus). 


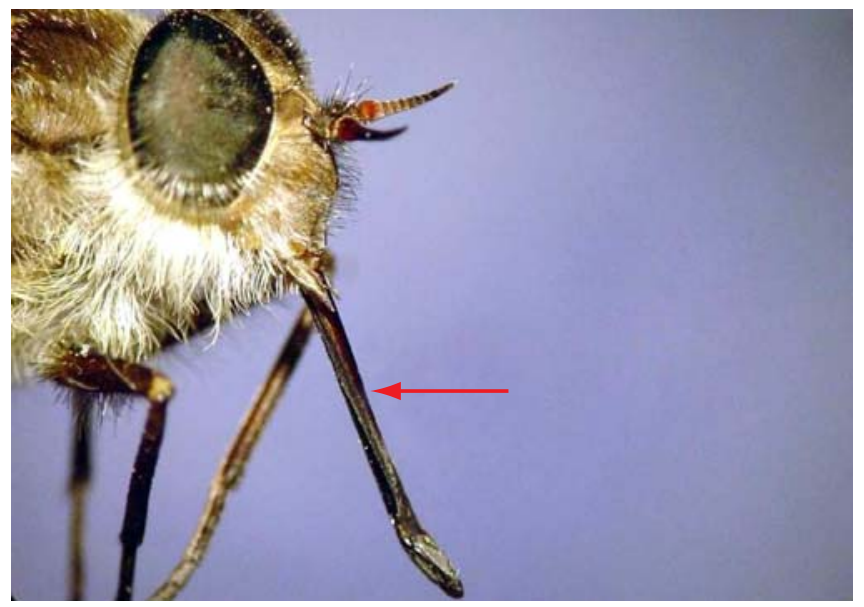

Figura 5. Comprimento da probóscide (Scaptia).

Figure 5. Proboscis length (Scaptia).

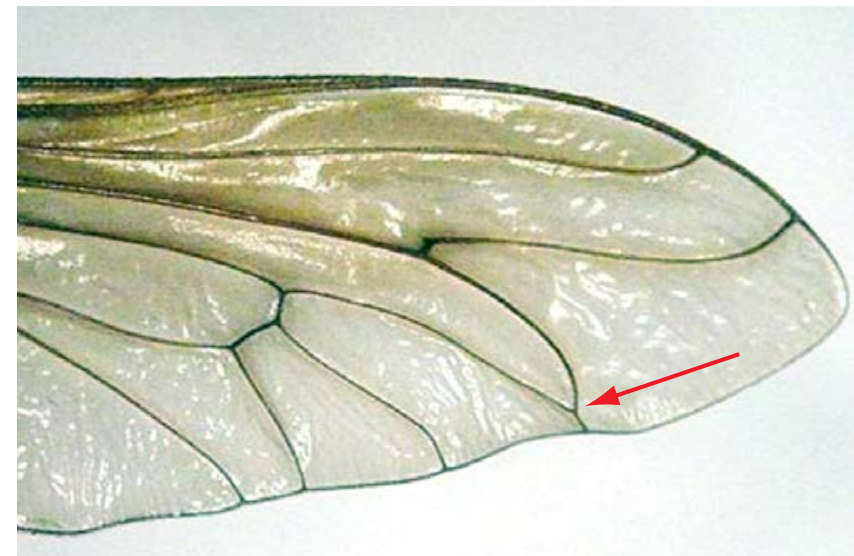

Figura 7. Célula r5 normalmente fechada (Fidena).

Figure 7. r5 cell usually closed (Fidena).

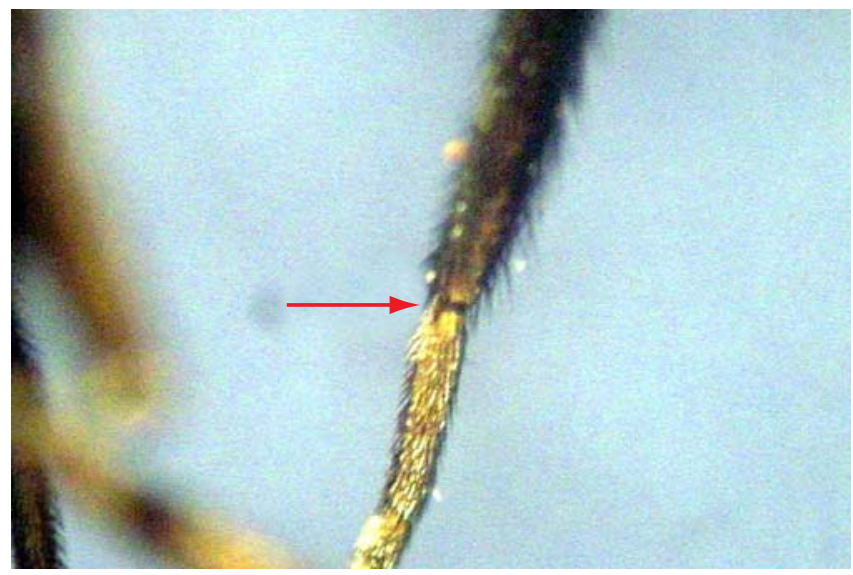

Figura 9. Espinhos apicais da tíbia posterior (vista ventral) presentes (Chrysops).

Figure 9. Apical spines on the posterior tibia present (ventral view, Chrysops).

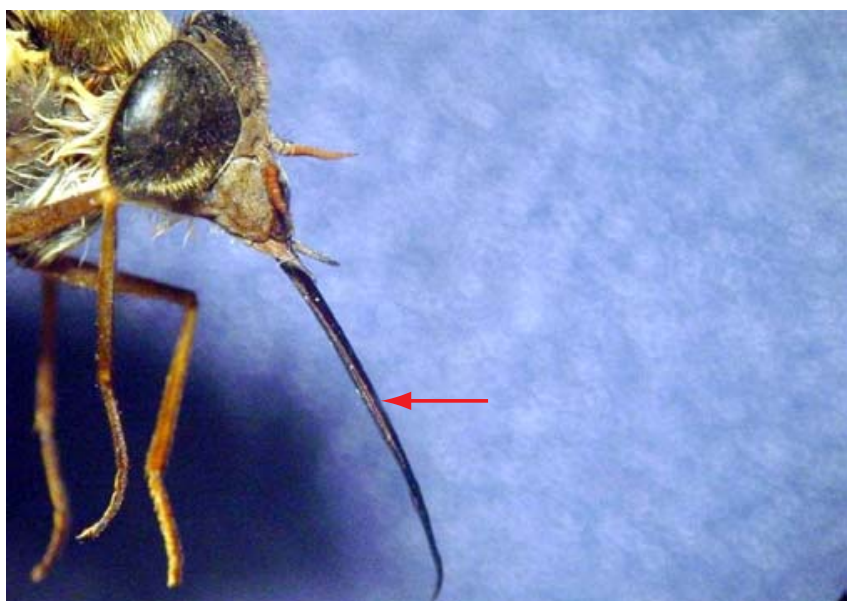

Figura 6. Comprimento da probóscide (Fidena).

Figure 6. Proboscis length (Fidena).

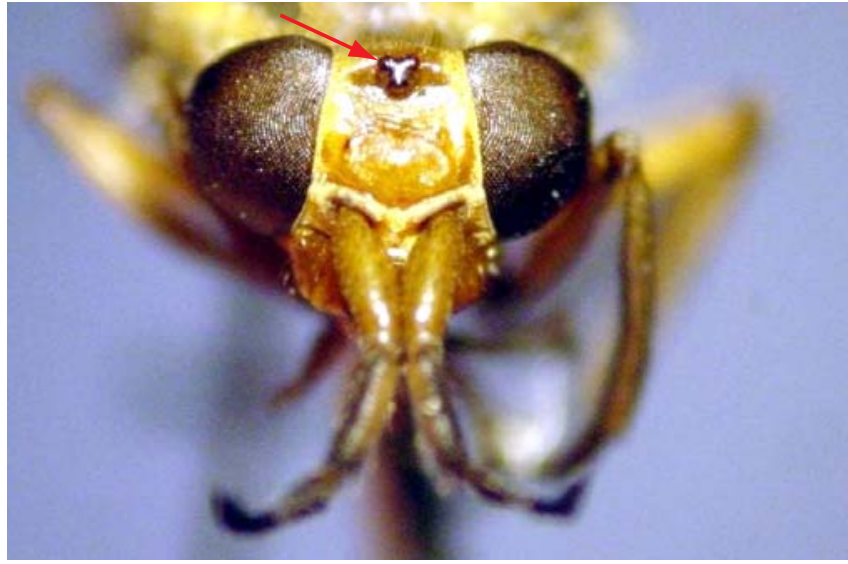

Figura 8. Ocelos presentes (Chrysops)

Figure 8. Oceli present (Chrysops).

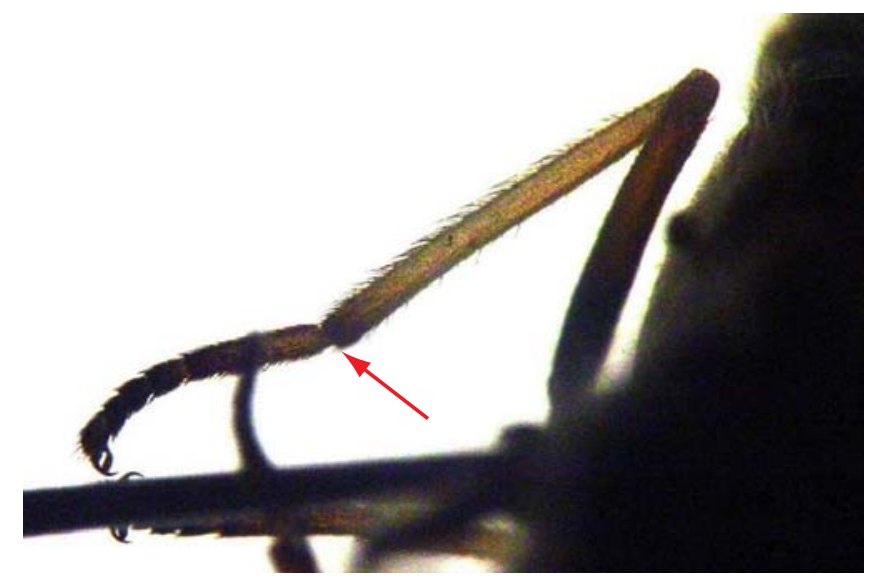

Figura 10. Espinhos apicais da tíbia posterior ausentes (Tabanus).

Figure 10. Apical spines on the posterior tibia absent (Tabanus). 


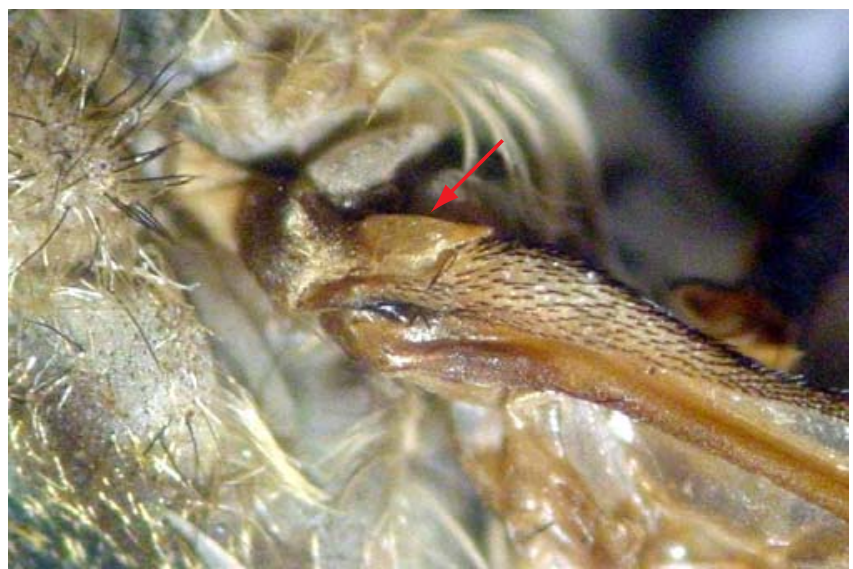

Figura 11. Basicosta sem cerdas (Dasybasis).

Figure 11. Basicosta lacking setae (Dasybasis).

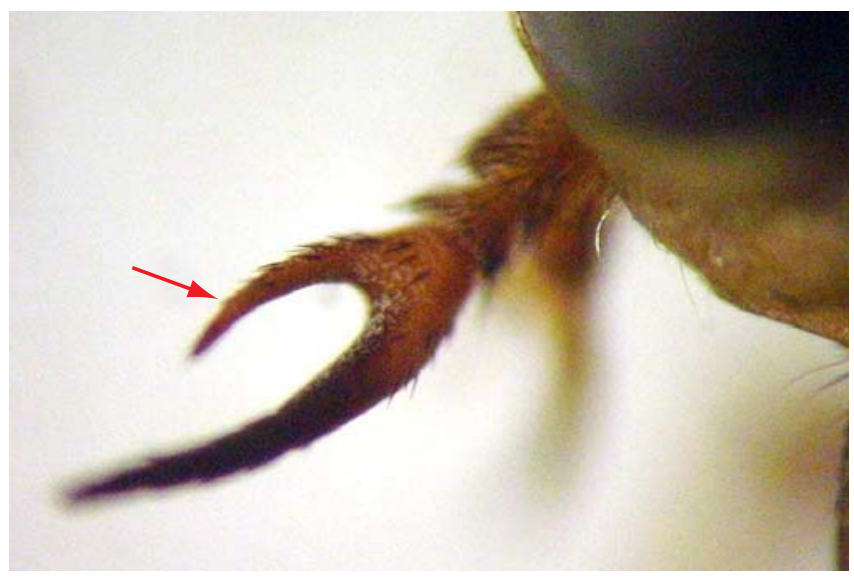

Figura 13. Longo espinho dorsal na base do flagelo (Dichelacera).

Figure 13. Base of flagellum with a long dorsal spine (Dichelacera).

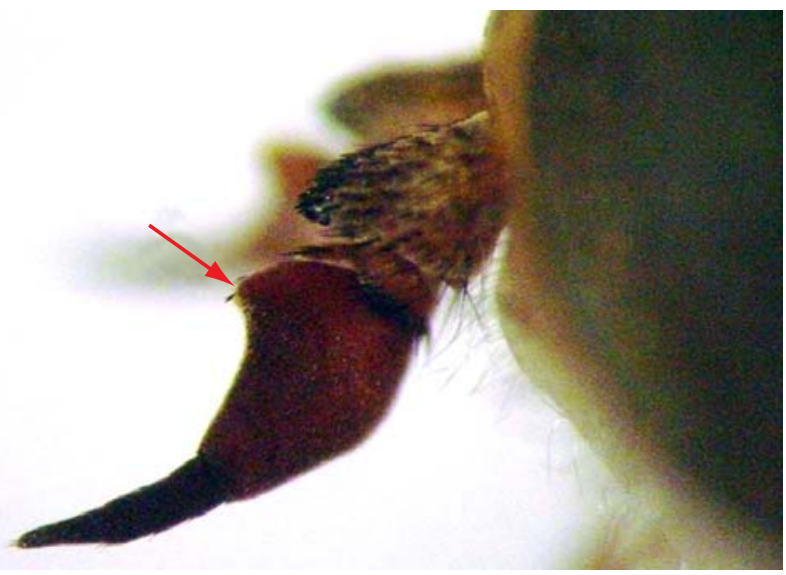

Figura 15. Base do flagelo no máximo com angulação obtusa dorsalmente (Tabanus).

Figure 15. Dorsal base of flagellum maximally at an obtuse angle (Tabanus).

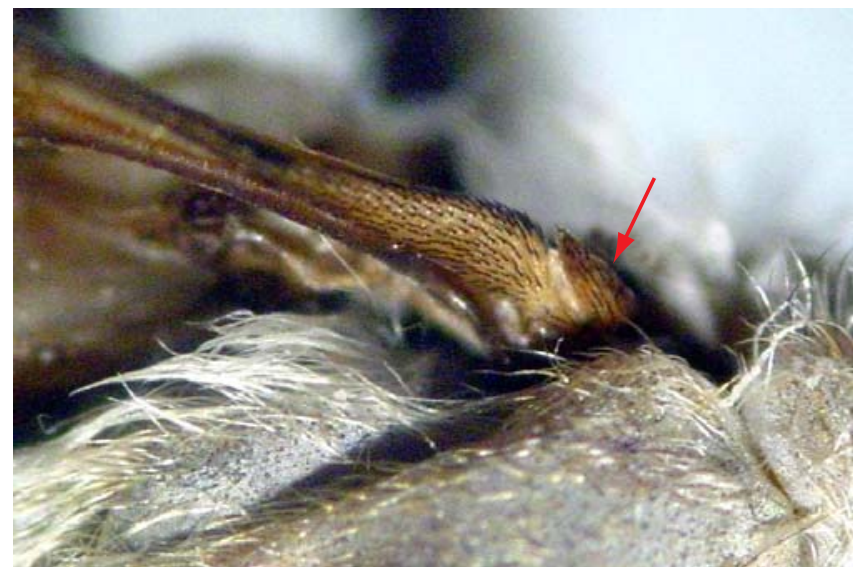

Figura 12. Basicosta com cerdas menos densas que nas adjacências da veia costa (Leucotabanus).

Figure 12. Setae on Basicosta less dense than in the area adjacent to the costal vein (Leucotabanus).

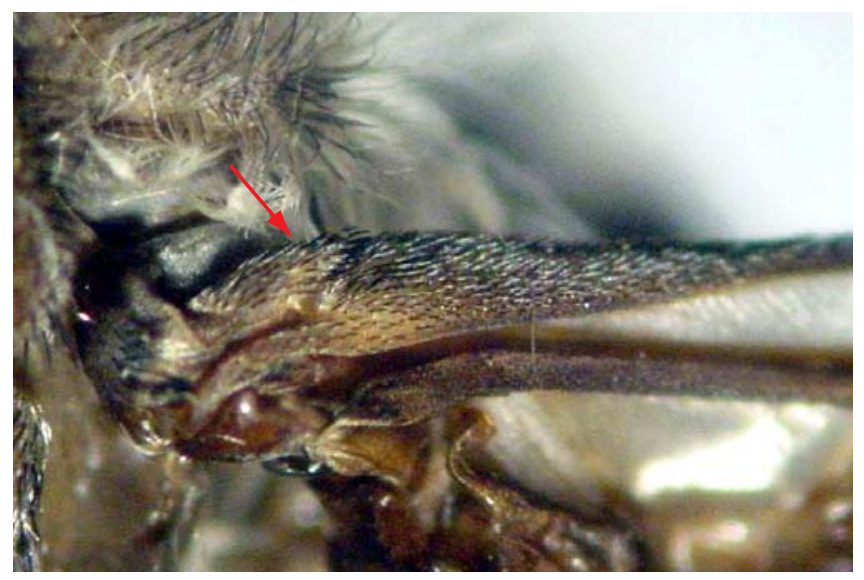

Figura 14. Basicosta densamente coberta de cerdas (Poeciloderas).

Figure 14. Basicosta densely covered with setae (Poeciloderas).

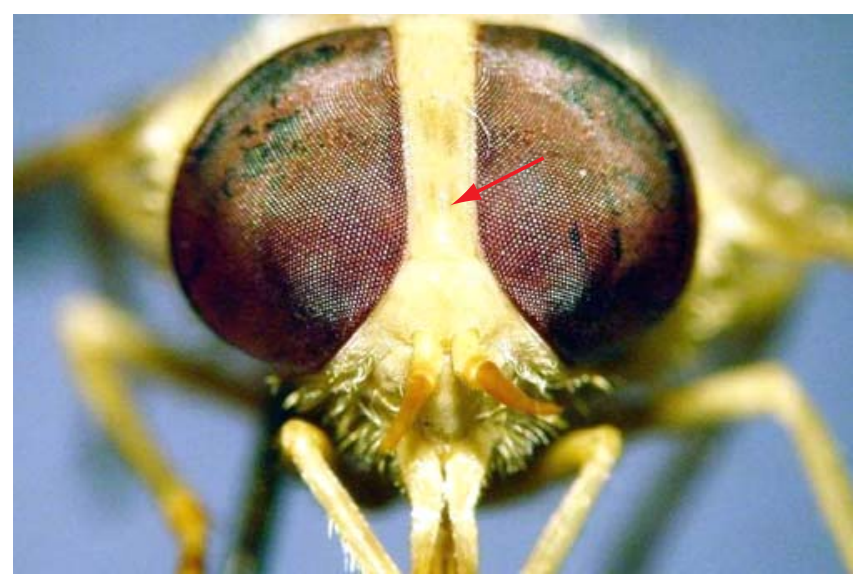

Figura 16. Calo frontal ausente (Chlorotabanus).

Figure 16. Frontal callus absent (Chlorotabanus). 


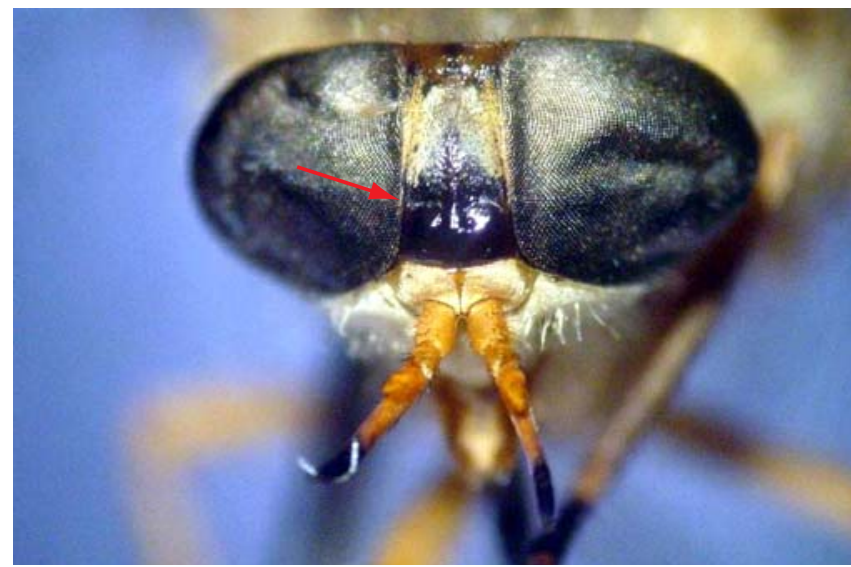

Figura 17. Calo frontal presente (Dichelacera).

Figure 17. Frontal callus present (Dichelacera).

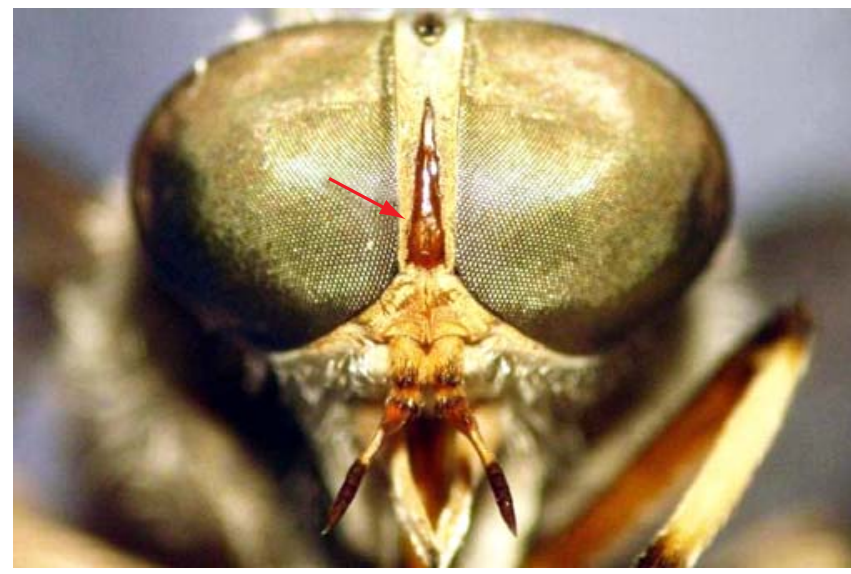

Figura 19. Calo frontal mais estreito que a fronte (Leucotabanus). Figure 19. Frontal callus more slender than frons (Leucotabanus).

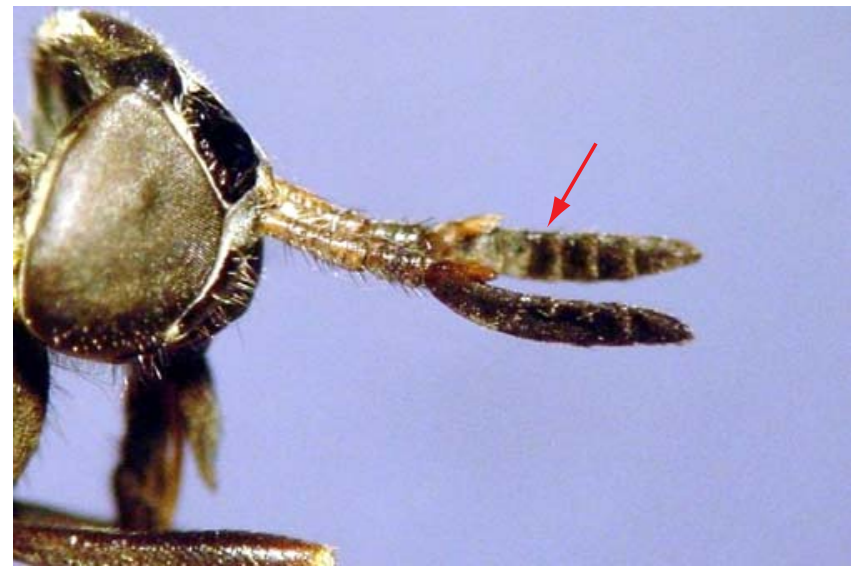

Figura 21. Antena longa (Acanthocera).

Figure 21. Antenna long (Acanthocera).

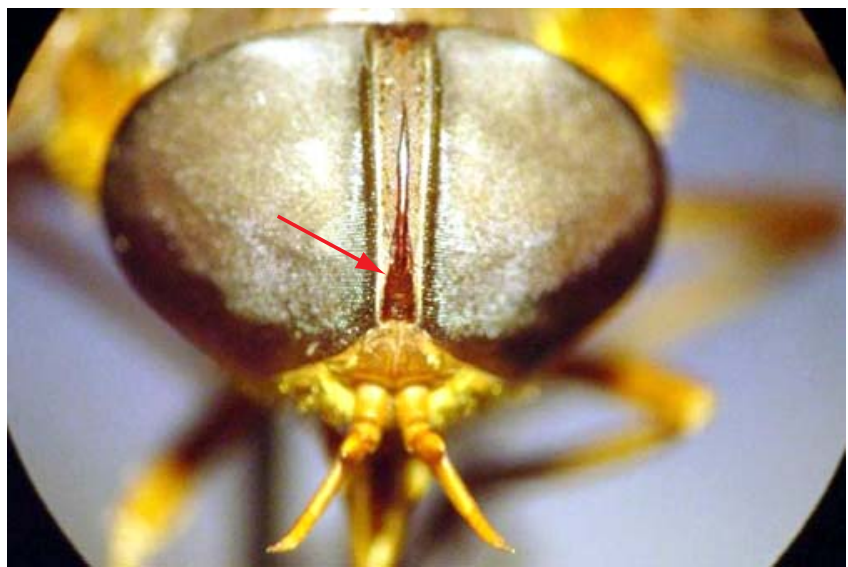

Figura 18. Calo frontal pequeno e estreito na base, geralmente com o ápice superior esbelto (Phaeotabanus).

Figure 18. Frontal callus small and narrow at base, generally slender at apex (Phaeotabanus).

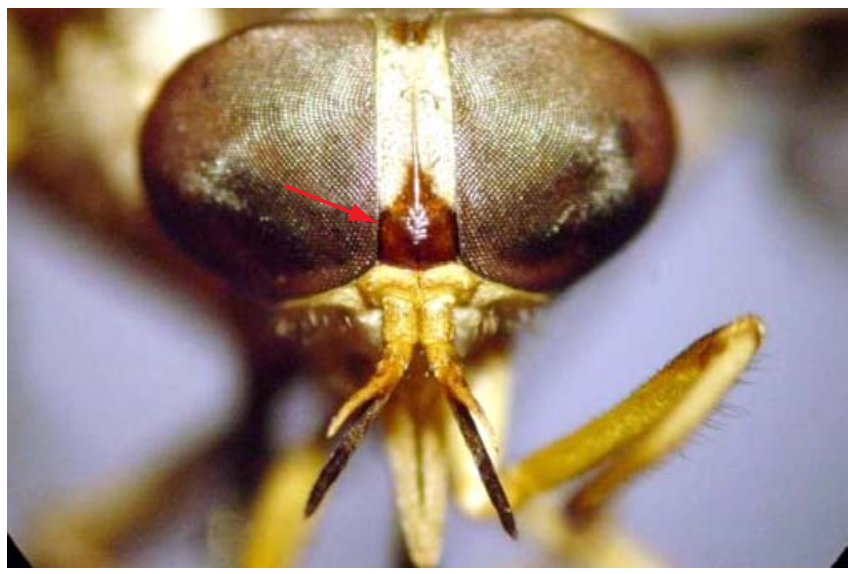

Figura 20. Calo frontal tão largo quanto à fronte (Dichelacera).

Figure 20. Frontal callus as wide as frons (Dichelacera).

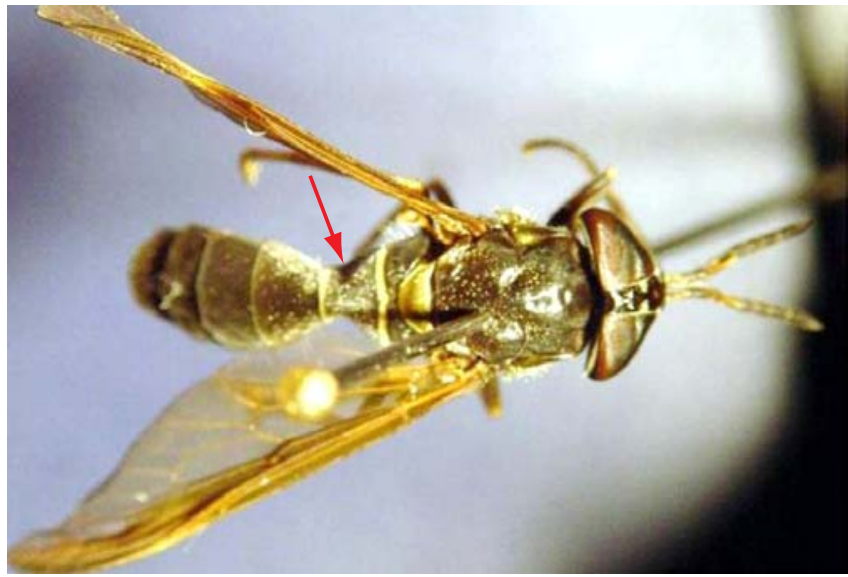

Figura 22. Corpo com distinta constrição na base do abdômen (Acanthocera).

Figure 22. Body with a distinctive constriction at the base of abdomen (Acanthocera). 


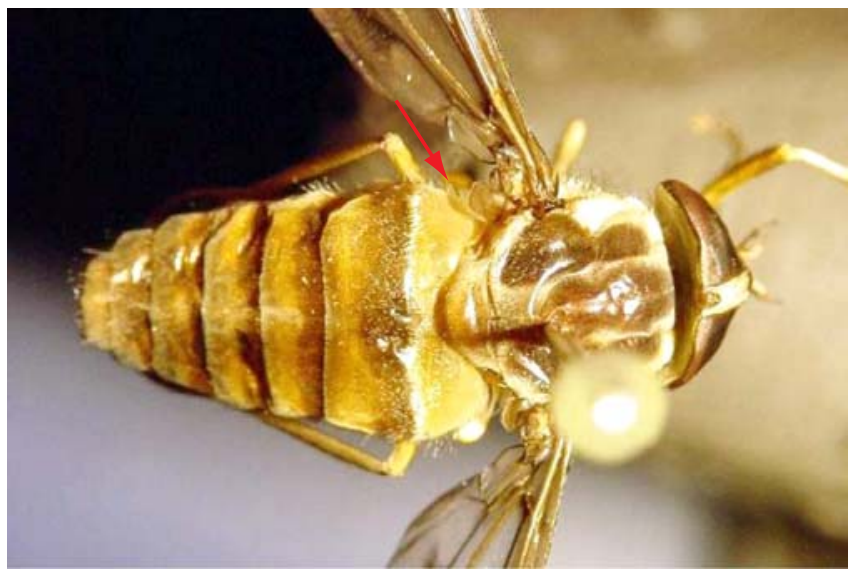

Figura 23. Corpo sem constrição na base do abdômen (Dichelacera).

Figure 23. Body without a constriction at the base of abdomen (Dichelacera).

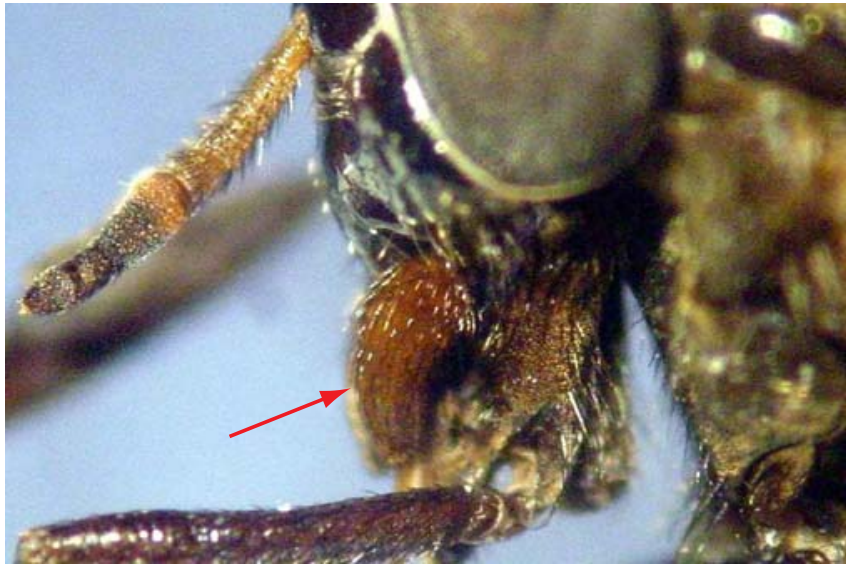

Figura 25. Segundo segmento do Palpo inflado (Lepiselaga).

Figure 25. Second palpal segment inflated (Lepiselaga).

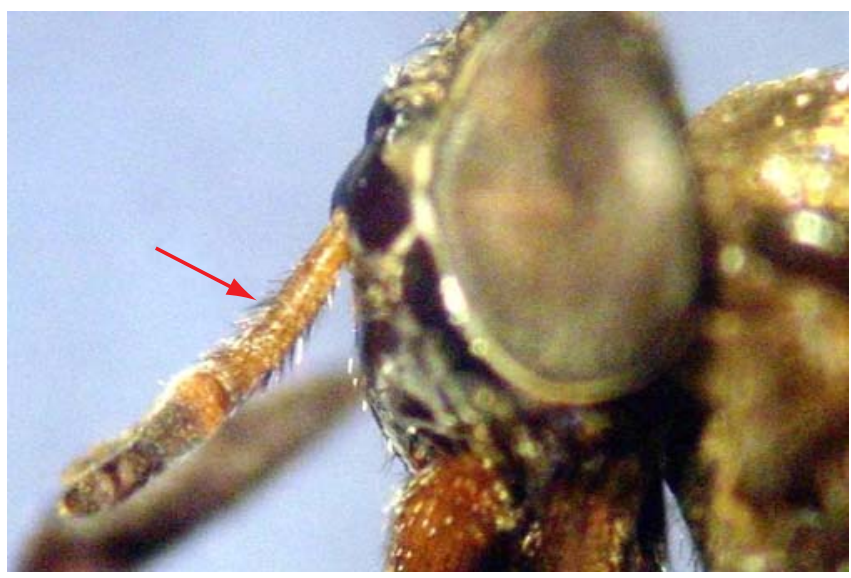

Figura 27. Escapo antenal longo (Lepiselaga).

Figure 27. Antennal scape long (Lepiselaga).

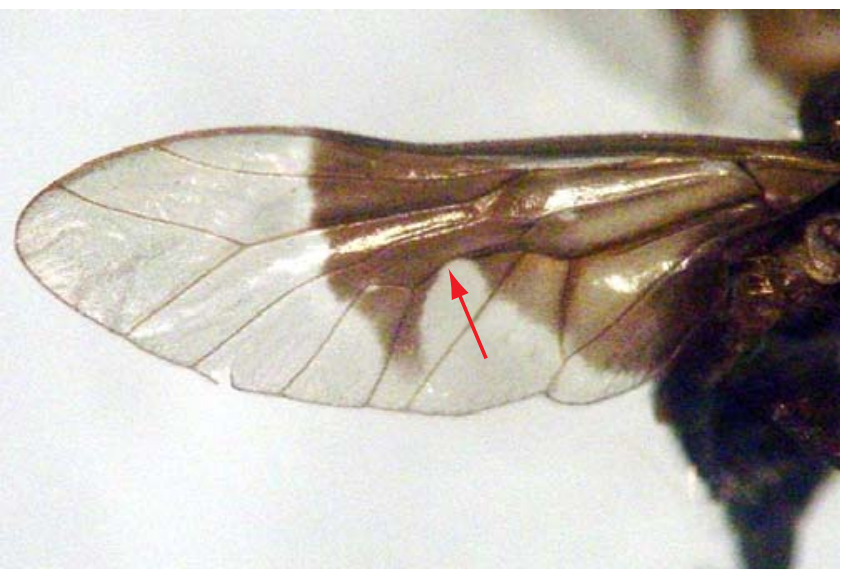

Figura 24. Célula discal da asa estreitada no meio (Lepiselaga).

Figure 24. Discal cell narrow at midlength (Lepiselaga).

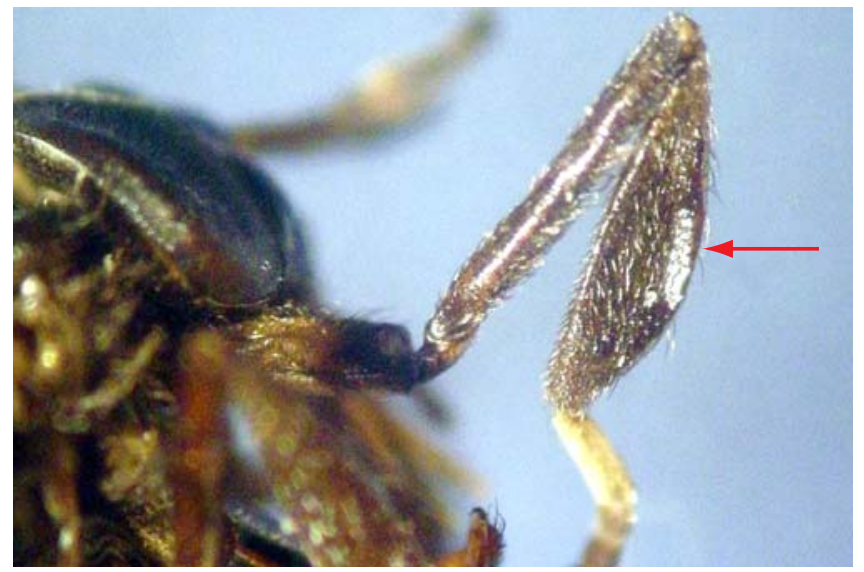

Figura 26. Tíbias infladas (Lepiselaga)

Figure 26. Tibia inflated (Lepiselaga).

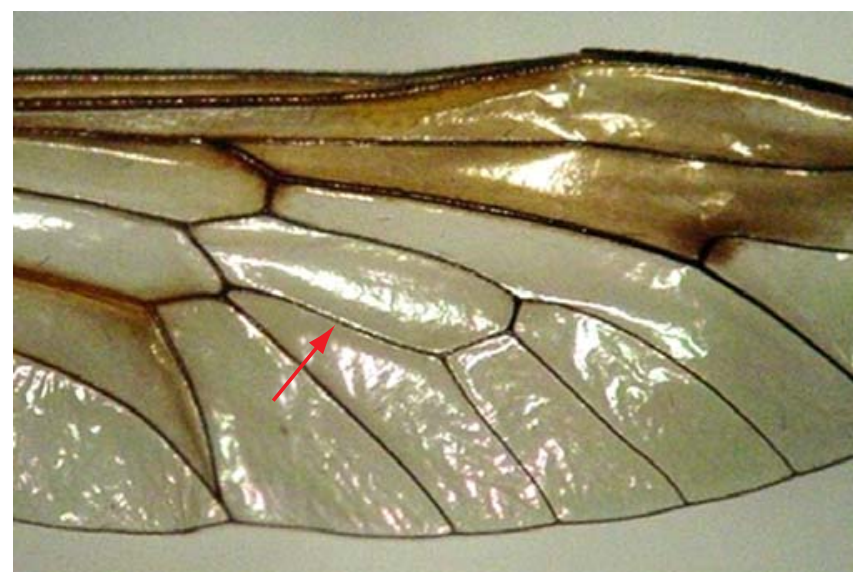

Figura 28. Célula discal da asa normal (Acanthocera).

Figure 28. Discal cell normal (Acanthocera). 


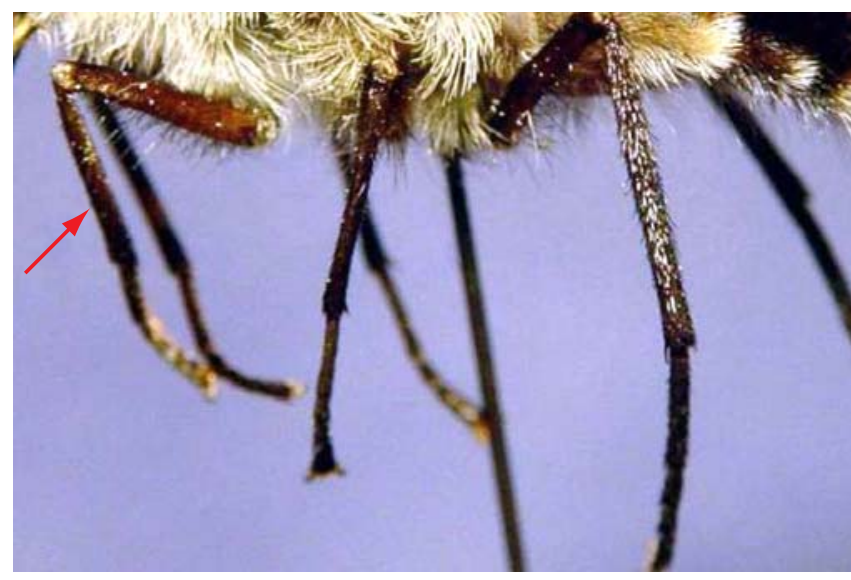

Figura 29. Tíbias delgadas (Scaptia).

Figure 29. Tibia slender (Scaptia).

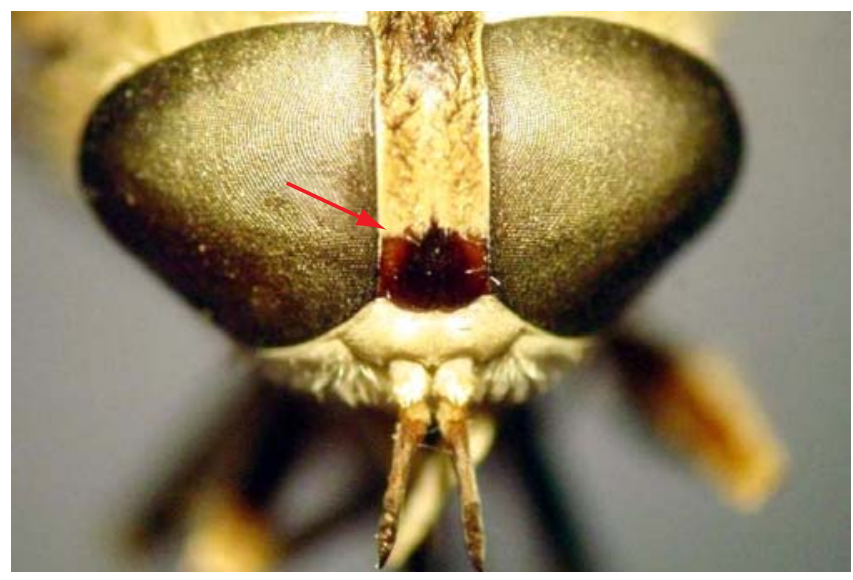

Figura 31. Calo com a base larga, tocando a margem interna dos olhos e a base da fronte em toda sua extensão (Dasybasis).

Figure 31. Callus wide at base, reaching the internal margin of the eyes and the entire length of the base of the frons (Dasybasis).

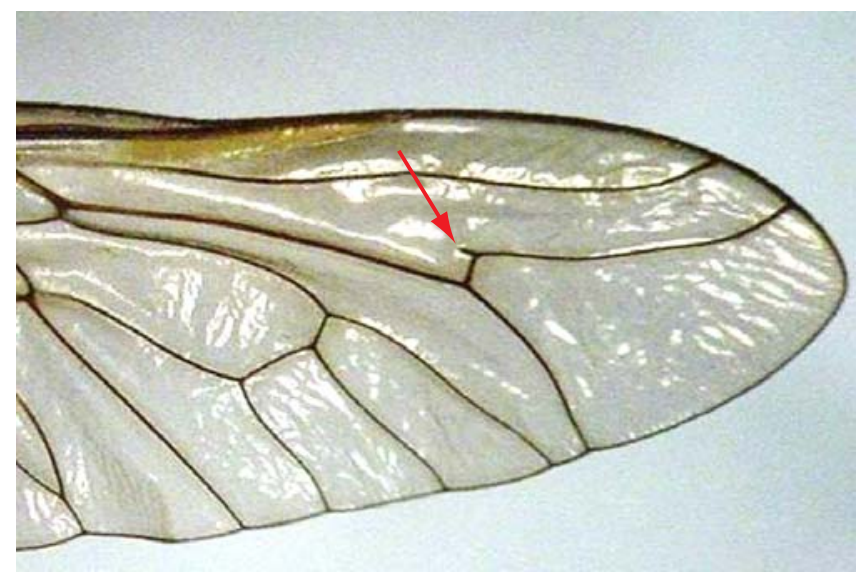

Figura 33. Apêndice na forquilha da veia r4 geralmente presente (Tabanus).

Figure 33. Spur at the $\mathrm{r} 4$ fork generally present (Tabanus).

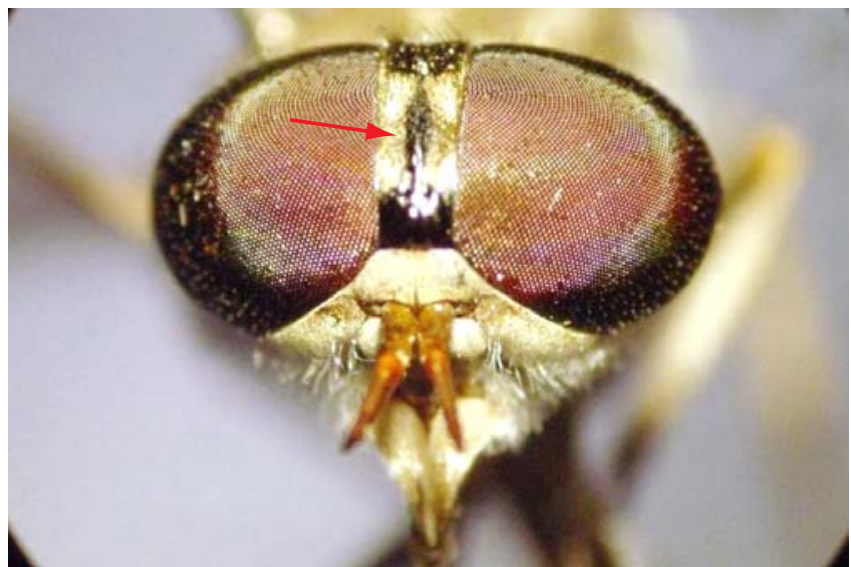

Figura 30. Fronte moderadamente larga, calo quadrado ou arredondado tão largo como a fronte (Stenotabanus).

Figure 30. Frons moderately wide, callus square-shaped or rounded and as wide as the frons (Stenotabanus).

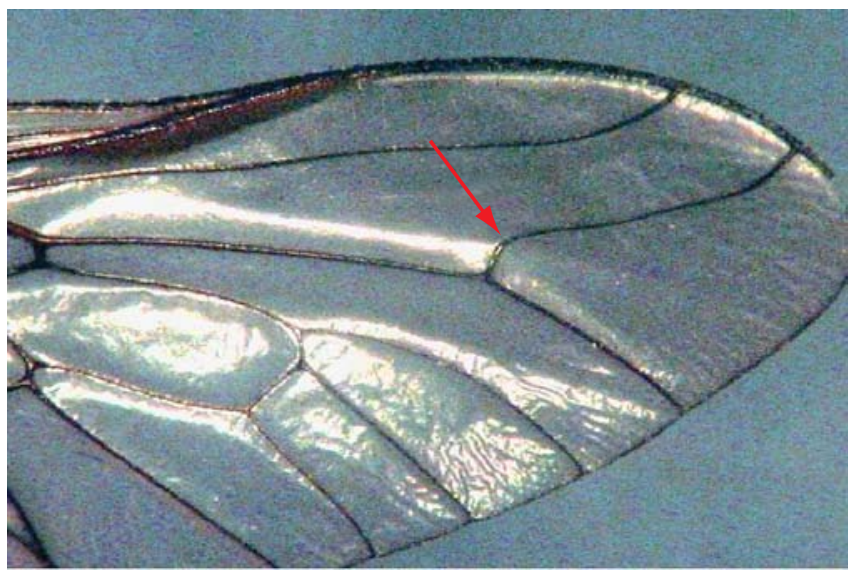

Figura 32. Apêndice na forquilha da veia r4 ausente (Leucotabanus).

Figure 32. Spur at the $\mathrm{r} 4$ fork absent (Leucotabanus).

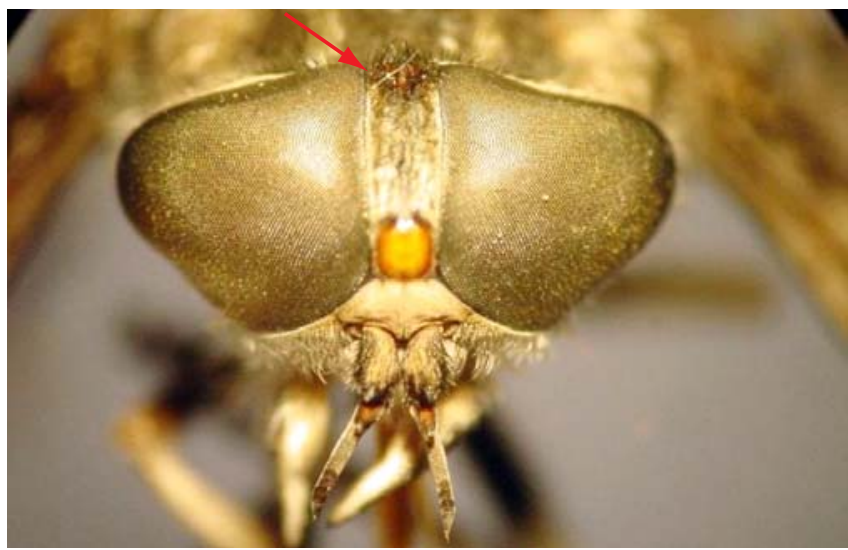

Figura 34. Vértice da cabeça com tubérculo ocelar pequeno e arredondado (Poeciloderas).

Figure 34. Head apex with a small, rounded ocellar tubercle (Poeciloderas). 


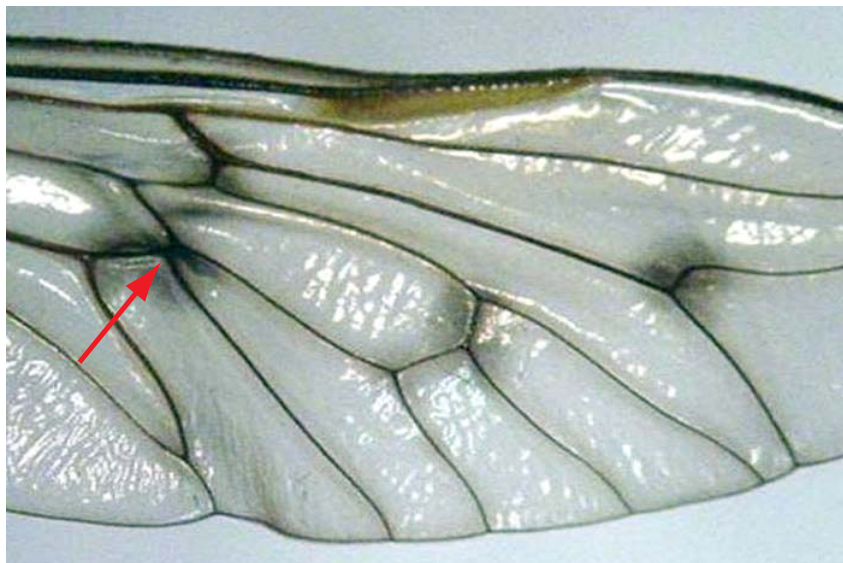

Figura 35. Asa com todas as veias transversais proeminentemente com manchas (Poeciloderas).

Figure 35. Wing with prominent spots on all transversal veins (Poeciloderas).

\section{Referências Bibliográficas}

COSCARÓN, S. 1968. Notas sobre tabánidos argentinos (Diptera) VI. El género Lepiselaga Macquart em la Argentina. Revta Soc. Ent. Argent. 30(1/4):51-59, il.

COSCARÓN, S. 1974b. Notas sobre tabánidos argentinos X. El género Dichelacera Macquart (Diptera-Insecta). Revta Soc. Ent. Argent. 34(3/4):229:242

COSCARÓN, S. 1975a. Notas sobre tabánidos argentinos (Diptera) IX. Los gêneros Stenotabanus Lutz y Myiotabanus Lutz (Diptera-Insecta). Comis. Invest. Cient. Prov. B. Aires, informe. 16:1-39, il.

COSCARÓN, S. 1975b. Notas sobre tabánidos argentinos XIII. El género Catachlorops Lutz em Argentina (Insecta-Diptera). Physis, B. Aires (C). 34(88):23-31, il.

COSCARÓN, S. 1976a. Notas sobre tabánidos argentinos XI. Sobre los géneros Leucotabanus Lutz, Pseudacanthocera Lutz, Bolbodimyia Bigot Y Pachyschelomyia Barreto (Diptera-Insecta). Revta Mus. Argent. Cienc. Nat. Bernardino Rivadavia, Ent. 5(5):89-103, il.

COSCARÓN, S. 1976c. Notas sobre tabánidos argentinos XIV. Sobre los géneros Diachlorus Osten Saken, Stibasoma Schiner, Stypommisa Enderlein, Cryptotylus Lutz y Chlorotabanus Lutz (Diptera). Revta Soc. Ent. Argent. 35(1/4):39-50, il.

COSCARÓN, S. 1978. Notas sobre tabánidos argentinos XVII. Los géneros Phaeotabanus Lutz y Acanthocera Macquart en la Argentina (TabanidaeDiptera). Revta Soc. Ent. Argent. 37(1/4):27:32, il.

COSCARÓN, S. 1979. Notas sobre tabánidos argentinos XV. El género Tabanus Linnaeus (Diptera- Insecta). Obra centenaria del Museo de La Plata, VI:251-278, 7 figs.

COSCARÓN, S. 1979b. Notas sobre tabánidos argentinos XVI. El género Chrysops Meigen (Diptera- Insecta). Acta Zool. Lilloana. 25:365-392, il

COSCARÓN, S. 2001. El gênero Fidena Walker 1850 em Argentina y Chile (Diptera: Tabanidae). Acta ent. Chilena 25:51-72.

COSCARÓN, S. \& G.B. FAIRCHILD. 1976. El género Poeciloderas

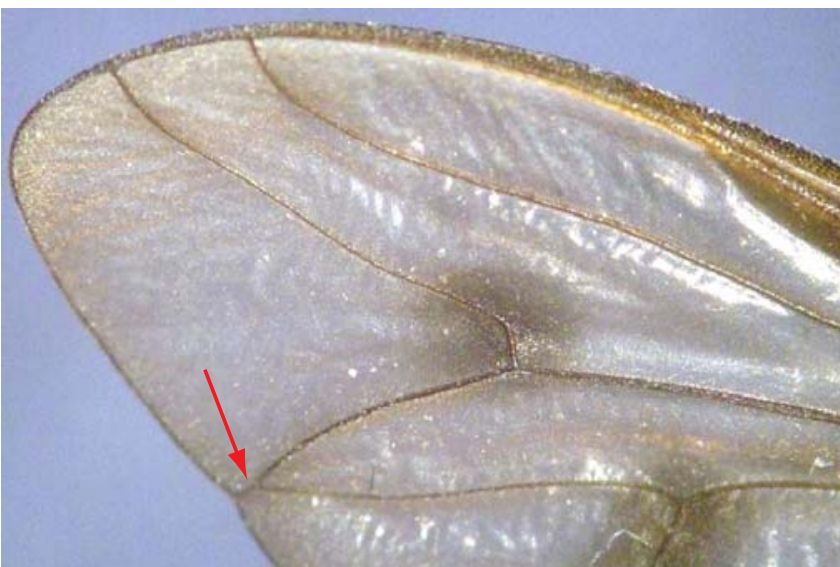

Figura 36. Célula r5 fechada ou estreitada (Poeciloderas).

Figure 36. $r 5$ cell closed or narrow (Poeciloderas).

Lutz em Argentina (Tabanidae, Diptera, Insecta). Physis, B. Aires (C) 35(91):293-401, il.

COSCARÓN, S. \& C.B. PHILIP. 1967a. Key to the neotropical species of Dasybasis Macquart. Segundas Jornadas entomoepidemiológicas argentinas. 1:95-103.

COSCARÓN, S. \& N. PAPAVERO. 1993. An illustrated manual for the identification of the Neotropical genera and subgenera of Tabanidae (Diptera). Museu paraense Emílio Goeldi, Coleção Emilie Snethlage, 150, p.il.

FAIRCHILD, G.B. 1969. Notes on Neotropical Tabanidae XII. Classification and distribution, with keys to genera and subgenera. Arq. Zool. S. Paulo, 17(4):199-255.

FAIRCHILD, G.B. \& J.F. BURGER. 1994. A catalog of the Tabanidae (Diptera) of the Americas south of the United States. Mem. Amer. Ent. Inst., $\mathrm{n}^{\circ} .55$.

FOIL, L.D. \& J.A. HOGSETTE. 1994. Biology and control of tabanids, stable flies and horn flies. Rev. sci. tech. Off. int. Epiz., 13(4):1125-1158.

FRANÇA, J.M. 1975. Sobre o comportamento de alguns tabanídeos do litoral e do primeiro planalto do estado do Paraná, Brasil (Diptera, Tabanidae). Dissertação de Mestrado.

KRINSKY, W.L. 1976. Animal disease agents transmitted by horse flies (Diptera: Tabanidae). Journal of Medical Entomology, 13(3):225-275

LECLERCQ, M. 1965. Tabanidae de la region neotropicale. Bull. Inst. Agron. De Gembloux, 33(3):377-380.

LUTZ, A.; H.C. SOUZA ARAÚJO \& O. FONSECA FILHO. 1918. Viagem scientifica no rio Paraná e a Asuncion, com volta por Buenos Aires, Montevideo e Rio Grande. Mem. Inst. Oswaldo Cruz, 10(2):104-173, figs.

MORRONE, J.J. 2005. Biogeographic áreas and transition zones of Latin América and the Caribbean islands base don panbiogeographic and cladistic analysis of the entomofauna. Annual Review of Entomology, 51:467-494.

TOWNES, H. 1972. A light-weight Malaise trap. Ent. News., 83:239-247.

WILKERSON, R.C. \& S. COSCARÓN. 1984. A review of South American Scaptia (Pseudoscione) (Diptera, Tabanidae). J. med. Ent. 21(2):213-236, il. 